\title{
AVALIAÇÃO DO POTENCIAL TERAPÊUTICO DE BACCHARIS DRACUNCULIFOLIA E PEUMUS BOLDUS NO PROCESSO FIBROSANTE HEPÁTICO
}

\author{
Caio Mateus da Silva ${ }^{1}$ \\ Brenda de Oliveira da Silva ${ }^{2}$ \\ Flávio Henrique Caetano ${ }^{3}$ \\ Karen Cristiane Martinez de Moraes ${ }^{4}$
}

\begin{abstract}
Resumo: As doenças do fígado são consideradas um problema de saúde mundial e ainda terapias eficientes não foram desenvolvidas para a maioria dessas patologias. Mais especificamente, a fibrose hepática é característica comum do início de várias das anomalias no órgão. Dentro desse contexto, a busca por novos fármacos é necessária e o uso de plantas medicinais tem ganhado destaque. Neste trabalho, foi avaliado os efeitos dos extratos de Baccharis dracunculifolia e Peumus boldus em culturas de células hepáticas estreladas $L X-2$ em relação as alterações na morfologia dos filamentos de actina do citoesqueleto e no núcleo celular em ensaios de microscopia e na avaliação do padrão de expressão de genes relacionados à processos de apoptose e marcadores clássicos da fibrose hepática. Nos resultados, para as concentrações testadas o extrato de $P$. boldus altera o perfil de expressão de genes relacionados a apoptose causando maior estresse celular e quebrando a homeostase celular quando observados os filamentos de actina. Enquanto que a planta B. dracunculifolia apresentou uma grande melhora na reorganização do citoesqueleto e diminuição do estresse celular.
\end{abstract}

Palavras-chave: Cultura celular; Fibrose hepática; Plantas medicinais.

\footnotetext{
1 Instituto de Biociências/Universidade Estadual Paulista - Campus Rio Claro, Brasil. E-mail: caiomateux@hotmail.com.

2 Pós-Graduação em Biotecnologia/Universidade Federal de Ouro Preto, Brasil. E-mail: brendabiologa@yahoo.com.br.

3 Instituto de Biociências/Universidade Estadual Paulista - Campus Rio Claro, Brasil. E-mail: fccaetano@rc.unesp.br.

4 Instituto de Biociências/Universidade Estadual Paulista - Campus Rio Claro, Brasil. E-mail: karenmor@rc.unesp.br.
} 